\title{
Report on Design and
} Failure Limits of SiC/SiC and FeCrAl ATF Cladding Concepts under RIA

Nuclear Technology

Research and Development

Approved for public release
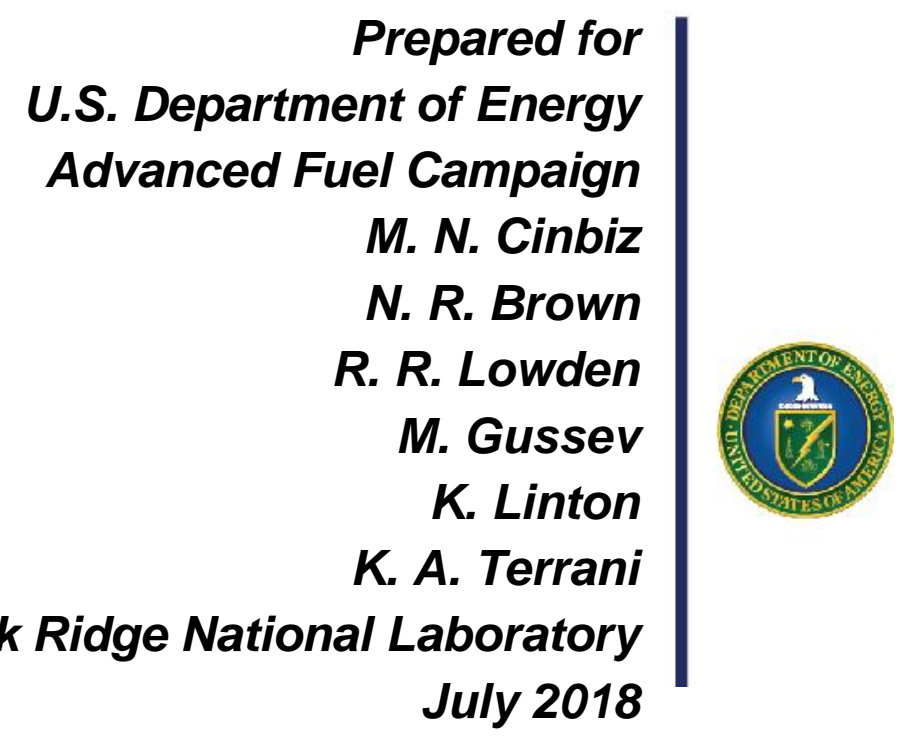

NT-M3FT-2018-204032 



\section{DISCLAIMER}

This information was prepared as an account of work sponsored by an agency of the U.S. Government. Neither the U.S. Government nor any agency thereof, nor any of their employees, makes any warranty, expressed or implied, or assumes any legal liability or responsibility for the accuracy, completeness, or usefulness, of any information, apparatus, product, or process disclosed, or represents that its use would not infringe privately owned rights. References herein to any specific commercial product, process, or service by trade name, trade mark, manufacturer, or otherwise, does not necessarily constitute or imply its endorsement, recommendation, or favoring by the U.S. Government or any agency thereof. The views and opinions of authors expressed herein do not necessarily state or reflect those of the U.S. Government or any agency thereof. 



\section{SUMMARY}

Pellet-cladding mechanical interaction (PCMI) is a possible failure scenario during a postulated reactivity-initiated accident (RIA). This report summarizes fiscal year 2018 research activities that were undertaken to evaluate the PCMI-like hoop strain-driven mechanical response of accident tolerant fuel cladding candidates of silicon carbide fiber/silicon carbide matrix composite ( $\mathrm{SiC} / \mathrm{SiC}$ ) and ironchromium-aluminum ( $\mathrm{FeCrAl}$ ) tube specimens. To achieve various RIA-like conditions, the modified-burst test device developed during fiscal years 2016 and 2017 was used. A heating capability was also added to the system for hightemperature testing of FeCrAl samples.

The first section of this report assesses the accuracy of the two-dimensional digital image correlation calculated strain values for tube samples. The speckle patterns are computer generated in a two-dimensional plane, and the generated images were wrapped into a cylindrical surface for the validation using digital image correlation technique on curved geometries. Subsequent sections address the failure behavior of $\mathrm{SiC} / \mathrm{SiC}$ composites and long-term heat treated and as-drawn $\mathrm{FeCrAl}$ alloy tubes at various strain rates relevant to the postulated RIA events. In the last part, the effect of possible design parameters of failure strain and the strain rate are discussed for $\mathrm{SiC} / \mathrm{SiC}$ composites and $\mathrm{FeCrAl}$ alloys during the PCMI phase of RIA.

Future work is planned to develop and design safety tests for accident tolerant fuel cladding candidates and the advanced fuel forms with respect to their transient responses. A broader perspective on the mechanical behavior of the unirradiated and irradiated accident tolerant fuel cladding candidates will be developed using the modified-burst test and other mechanical tests. 


\section{CONTENTS}

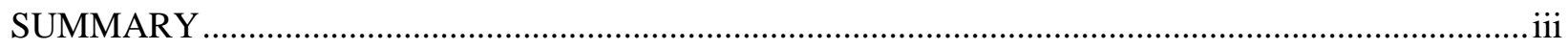

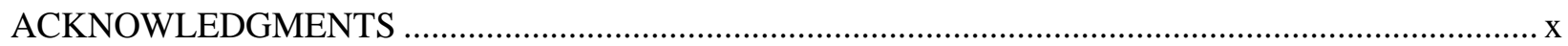

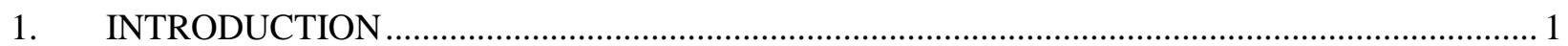

2. ASSESSMENT OF THE DIC STRAIN CALCULATIONS …..................................................... 2

3. FAILURE BEHAVIOR OF SiC/SiC COMPOSITES DURING PCMI LOADING ........................5

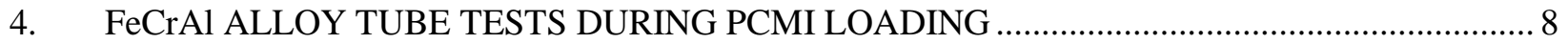

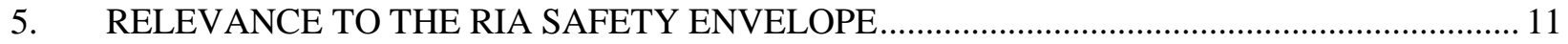

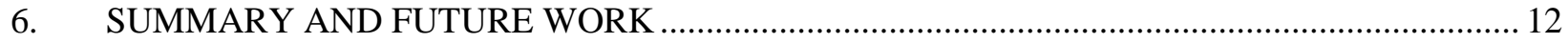

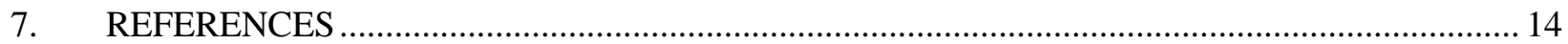




\section{FIGURES}

Figure 1. (a) Schematics of the camera and telecentric lens system, which is reinforced with mirrors. (b) Projections of SiC/SiC composite sample on the camera system. The sample was dyed with black and white paint to create speckle patterns. The white frames show typical DIC-objects $(85 \mathrm{px} \times 85 \mathrm{px})$ to determine the surface strains on the samples. (c) A schematic of the MBT for the PCMI-type loading............................................

Figure 2. Computer-generated reference pictures for assessment of the DIC software. (a) PST

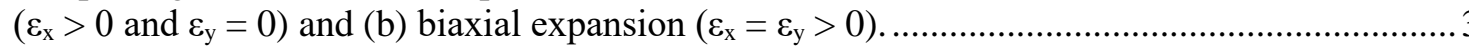

Figure 3. Effect of subset size on DIC-calculated strains for the PST case [10]. Strain was applied only in the $x$-direction; strain in the $y$-direction was zero

Figure 4. Comparison of the accuracy values in the original and the $360^{\circ}$-wrapped pictures of two cases: (a) only $x$-direction strain applied and (b) both $x$ - and $y$-direction strains applied.....

Figure 5. Effects off-axis subset on the accuracy value.

Figure 6. Projections of a $\mathrm{SiC} / \mathrm{SiC}$ composite sample that was tested at a pressurization rate of. 3 $\mathrm{GPa} / \mathrm{s}$

Figure 7. (a) Evolution of the engineering strain and the internal pressure of the driver tube.

(b) Outer surface of the $\mathrm{SiC} / \mathrm{SiC}$ composite samples at the moment of failure. White line depicts the major hoop crack that yielded failure. Yellow lines show cracks branching out from the major hoop crack, and the red line is a surface crack on the fibers.

Figure 8. FeCrAl samples for MBT tests. The Gen-I alloys were subjected to a long-term heat treatment.

Figure 9. High-temperature setup for MBT. (a) An insulated box is placed outside the sample, heaters, and mirrors during heating. (b) The insulated box was not used during mechanical tests so that the DIC could be used. (c) Sample reflections and the location of the thermocouple.

Figure 10. The cooling behavior of the dummy sample after the insulated box was removed. 10

Figure 11. Four reflections of the FeCrAl sample. (a) Before test and (b) during rupture. 11

Figure 12. Example calculated pulse widths of a typical RIA in an LWR for different neutron generation times ranging from 10 to $30 \mu \mathrm{s}$ and reactivity insertions, calculated using point kinetics with one-dimensional thermal feedback.

\section{TABLES}

Table 1. Summary of the mechanical test results of $\mathrm{SiC} / \mathrm{SiC}$ composites. 7

Table 2. Results of the mechanical testing of the FeCrAl alloy 


\section{ACRONYMS}

ATF accident tolerant fuel

DIC digital image correction

FeCrAl iron-chromium-aluminum

LWR light water reactor

MBT modified-burst test

PCMI pellet cladding mechanical interaction

PST plane-strain tension

RIA reactivity-initiated accident

$\mathrm{SiC} \quad$ silicon carbide

$\mathrm{SiC} / \mathrm{SiC} \quad$ silicon carbide fiber/silicon carbide matrix

TREAT Transient Reactor Test Facility 


\section{ACKNOWLEDGMENTS}

This work was supported by the US Department of Energy Office of Nuclear Energy Advanced Fuels Campaign. The authors thank Daniel M. Wachs of Idaho National Laboratory for his oversight of this area. 



\section{REPORT ON DESIGN AND FAILURE LIMITS OF SiC/SiC AND FeCrAI ATF CLADDING CONCEPTS UNDER RIA}

\section{INTRODUCTION}

Accident tolerant fuel (ATF) materials must maintain or improve the reactor performance and safety characteristics of the present uranium dioxide and zirconium-based cladding alloy fuel systems during normal operation, operational transients, and postulated design-basis accidents such as a loss of coolant accident or a reactivity-initiated accident (RIA) in light water reactors (LWRs) [1]. However, performance of the candidate ATF cladding materials is not yet fully understood for conditions that simulate the pelletcladding mechanical interaction (PCMI) due to rapid thermal expansion of the fuel during a postulated RIA.

A postulated RIA occurs because of a control rod-ejection accident in a pressurized water reactor or a control rod-drop accident in a boiling water reactor [2]. Both events cause a prompt increase in the fission rate density until negative fuel temperature feedback, mainly due to the Doppler effect, terminates fission reactions. However, the deposited energy causes a fast temperature increase in the fuel pellets, which results in rapid thermal expansion of the fuel. If the fuel-cladding gap closes before or during the RIA, the thermal expansion of the fuel imposes a mechanical strain on the inner surface of the cladding at a high strain biaxiality due to the isotropic thermal expansion of the uranium dioxide $\left(\mathrm{UO}_{2}\right)$ fuel pellets. Because the time scale of a postulated RIA is in the range of 10-200 ms for LWRs [3], the cladding is expected to deform at high strain rates up to $5 \mathrm{~s}^{-1}$ [2].

Separate effects tests inform the design of integral effects tests to investigate the transient response of the ATF fuel rods during RIA-relevant conditions and enable development of models for nuclear fuel safety. To support the design of future in-pile integral experiments and to capture distinct reactor kinetics of distinct LWR designs, the separate effects test is a vital tool that can be used to replicate the time scale of an RIA event by mimicking the mechanical loading conditions that result from the energy input during the RIA. The modified-burst test (MBT), compared to other mechanical tests, offers a uniform straining of the cladding and strain rates similar to postulated RIA scenarios [4, 5]. Consequently, pulse-controlled MBT equipment has been developed [5] with the capability of $360^{\circ}$-view digital image correlation (DIC) during fiscal year (FY) 2017 [6]. The arrangement of the DIC system and mirrors, a picture of a typical sample, and the working principle of the MBT are shown in Figure 1a-c. 

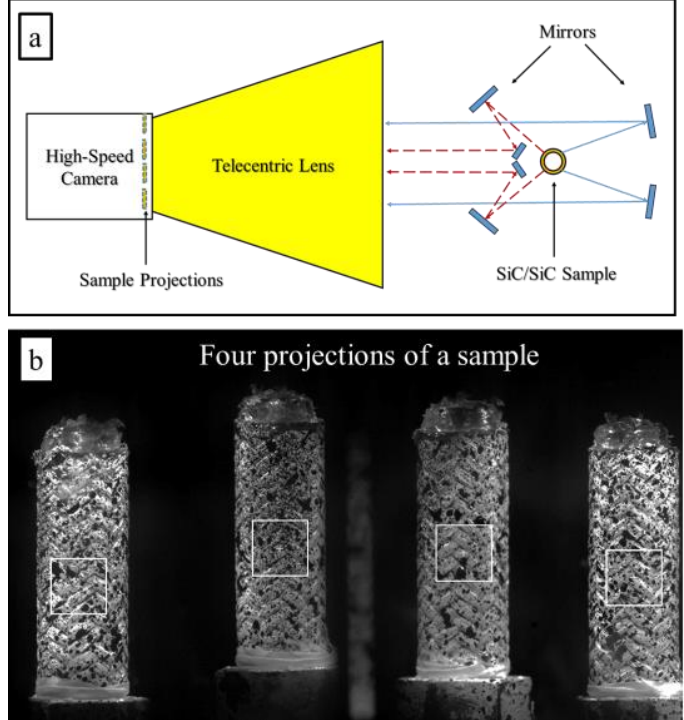

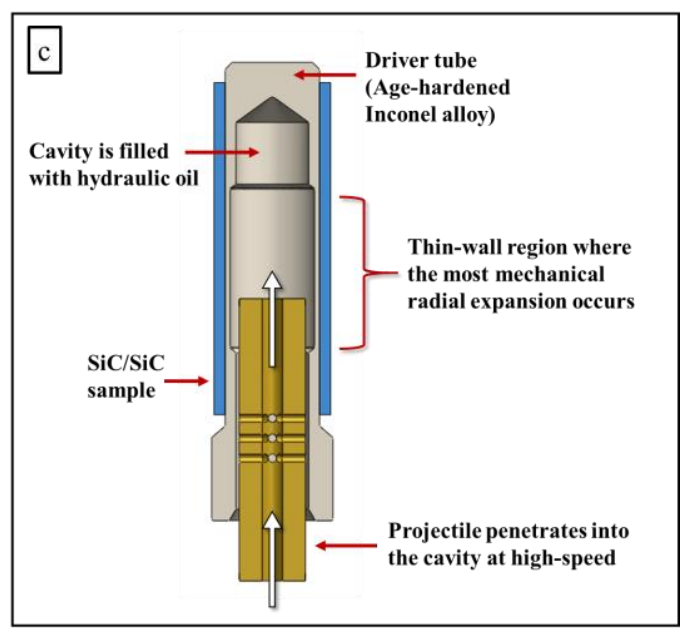

Figure 1. (a) Schematics of the camera and telecentric lens system, which is reinforced with mirrors. (b) Projections of $\mathrm{SiC} / \mathrm{SiC}$ composite sample on the camera system. The sample was dyed with black and white paint to create speckle patterns. The white frames show typical DIC-objects $(85 \mathrm{px} \times 85 \mathrm{px})$ to determine the surface strains on the samples. (c) A schematic of the MBT for the PCMI-type loading.

The first section of this report assesses accuracy of the two-dimensional (2-D) DIC calculated strain values for tube samples. The speckle patterns are computer generated in a 2-D plane, and the generated images have been wrapped into cylindrical geometry for the assessment of the accuracy of using DIC technique on tube samples. The second section addresses the failure behavior of the $\mathrm{SiC} / \mathrm{SiC}$ composites at various strain rates relevant to the postulated RIA events. The third section investigates the mechanical response of heattreated and as-drawn $\mathrm{FeCrAl}$ alloy tubes during a PCMI-like loading at elevated temperature of $250{ }^{\circ} \mathrm{C}$. The last section discusses the possible design parameters of $\mathrm{SiC} / \mathrm{SiC}$ composites and $\mathrm{FeCrAl}$ alloys with respect to the RIA.

\section{ASSESSMENT OF THE DIC STRAIN CALCULATIONS}

A DIC system was developed to offer high resolution measurements of the failure strain for each tube sample. To verify the performance of the system, we assessed the accuracy of mechanical strain calculations on a curved surface. To achieve that, images with 2-D random speckle patterns were generated by an approach suggested by Bing et al. [7] at similar resolutions as the images acquired during experiments (see Figure $2 \mathrm{a}$ and $\mathrm{b}$ ). Mechanical strain was imposed by applying pixel-based strains ( $\Delta$ pixel/pixel) up to $20 \%$ for two distinct strain paths: (i) plane-strain tension (PST) of the cladding tubes $\left(\varepsilon_{\mathrm{x}}>0\right.$ and $\varepsilon_{\mathrm{y}}=0$, Figure 2a) [2] and (ii) biaxial expansion, which is the postulated RIA strain path $[2,8,9]\left(\varepsilon_{x}=\varepsilon_{y}>0\right.$,Figure $\left.2 b\right)$. After applying the prescribed strains, the images with generated speckle patterns of each strain value were wrapped to form a tube with a $360^{\circ}$ surface like that of the experiments. The accuracy value of 2-D DIC was investigated by determining the difference between the imposed and the DIC-calculated strains for each loading case. The smaller accuracy value corresponded to a lesser error in the DIC-strain calculation and better strain calculation. 

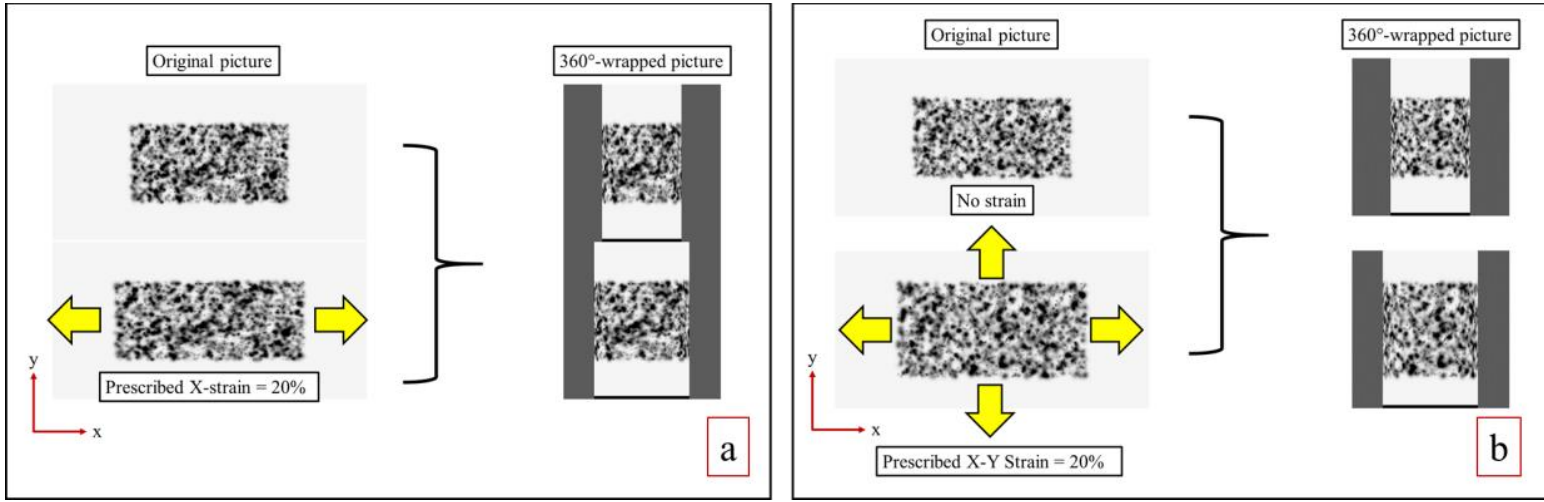

Figure 2. Computer-generated reference pictures for assessment of the DIC software. (a) PST ( $\varepsilon_{\mathrm{x}}>0$ and $\left.\varepsilon_{\mathrm{y}}=0\right)$ and (b) biaxial expansion $\left(\varepsilon_{\mathrm{x}}=\varepsilon_{\mathrm{y}}>0\right)$.

Figures $3 \mathrm{a}$ and $\mathrm{b}$ show the calculated strains of the wrapped pictures at the prescribed strain values. Strain was calculated at the same location for all subsets with a size of 31, 45, and $63 \mathrm{px}$ (Figure 3c). The accuracy value of the 31-px subset was higher than the other two at each prescribed strain, as shown in Figure $3 \mathrm{~d}$. The average accuracy values were also estimated as 253,88 , and $86 \mu \varepsilon$ for subset sizes of 31 , 45 , and $63 \mathrm{px}$, respectively. Note that accuracy value, in general, showed a monotonic increase for all cases below $1 \%$ strain and showed random behavior above $2 \%$ strain.
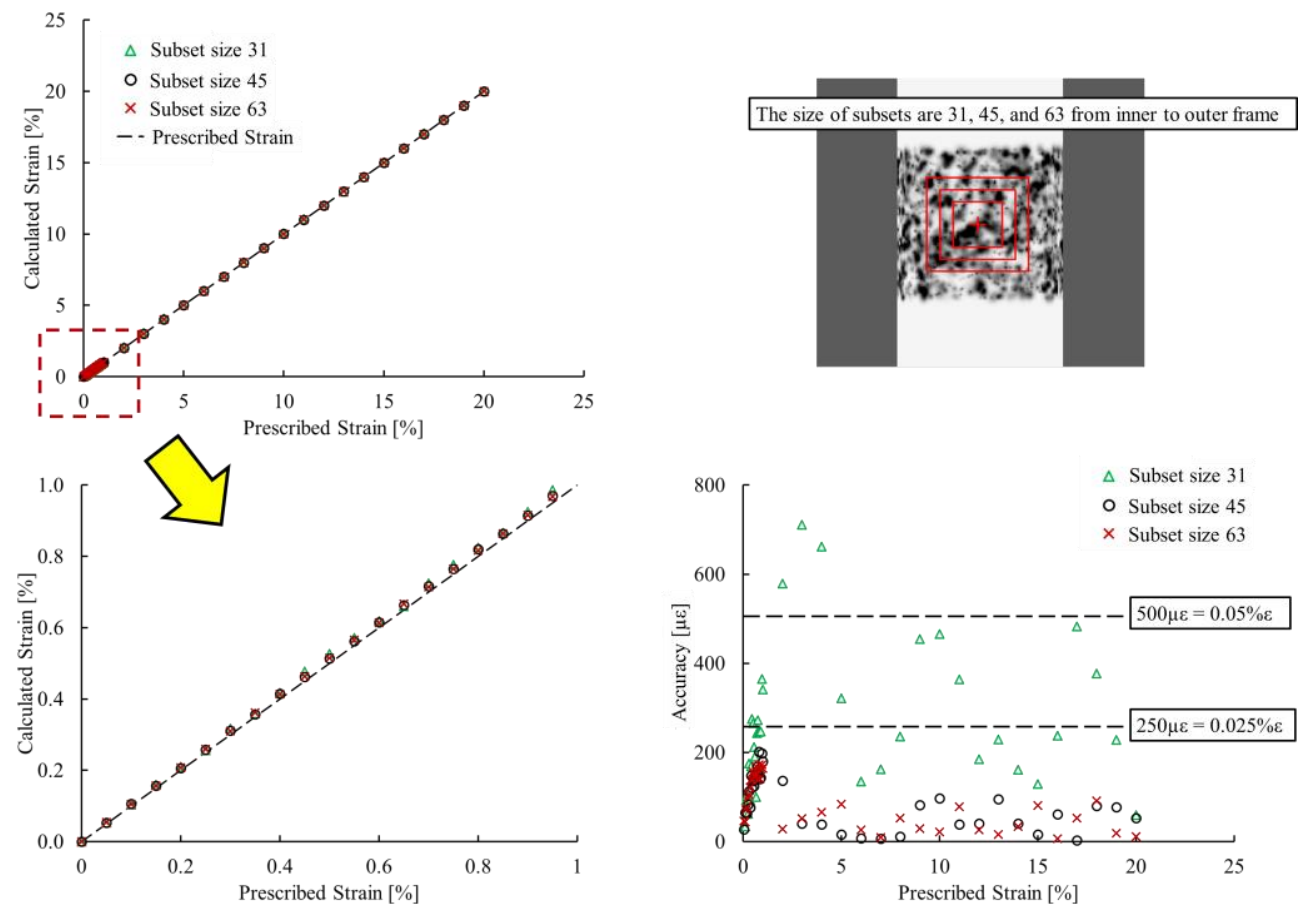

Figure 3. Effect of subset size on DIC-calculated strains for the PST case [10]. Strain was applied only in the $x$-direction; strain in the $y$-direction was zero.

Figure 4 illustrates the inaccuracies of the DIC-calculated strain in the plane-strain and biaxial expansion cases. Accuracy was determined to be better than $200 \mu \varepsilon$ for both test cases. The average accuracy value calculated from the original picture (no wrapping) was lower (76 and $47 \mu \varepsilon$ for PST and biaxial expansion, respectively) than the accuracy value determined after $360^{\circ}$-wrapping of the original picture ( 86 and $84 \mu \varepsilon$ for PST and biaxial expansion, respectively). The results indicate that the accuracy value of the strain determined from a curved object increased compared to the original picture, but this increase was below $37 \mu \varepsilon$ (maximum for all cases). 

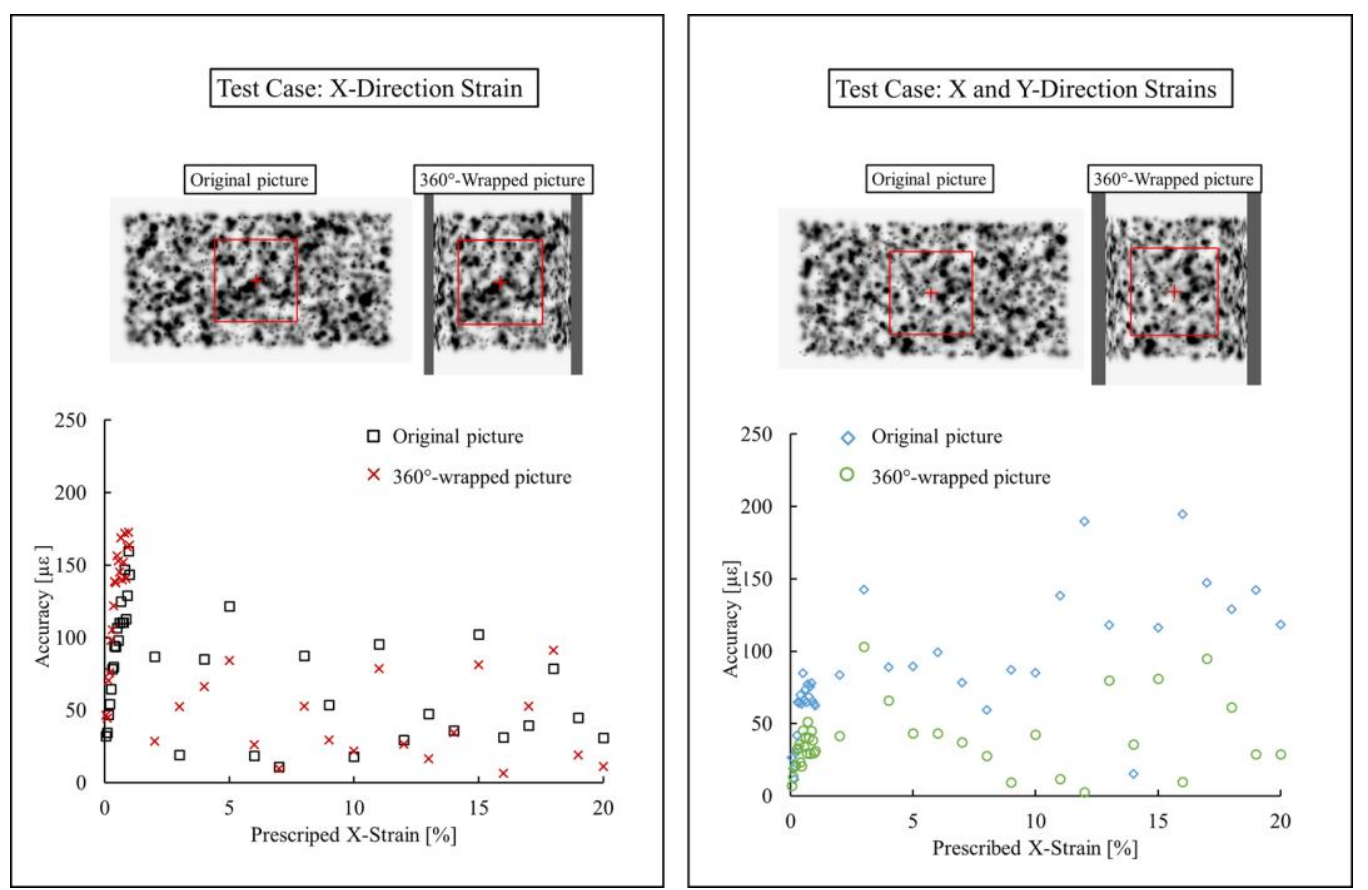

Figure 4. Comparison of the accuracy values in the original and the $360^{\circ}$-wrapped pictures of two cases: (a) only $x$-direction strain applied and (b) both $x$ - and $y$-direction strains applied.

Another important parameter for the strain calculations is the location of the subset due to the curved surface of the tube samples. Therefore, the effect of off-axis locations on the strain calculation was investigated. Figure 5 shows the value of the inaccuracy for two off-axis locations, A and B. At location A, the accuracy value was determined to be high (maximum value of) at low $(<1 \%)$ strains, and was determined to be lower at high $(>2 \%)$ strains. At location B, a reverse behavior was determined compared to location A. The average accuracy values were calculated as 237 and $130 \mu \varepsilon$ for locations $\mathrm{A}$ and B; and the maximum values were 469 and $330 \mu \varepsilon$ for the same locations, respectively. Hence, the accuracy of the strain increased when the subset was at an off-axis location for the tube sample. 


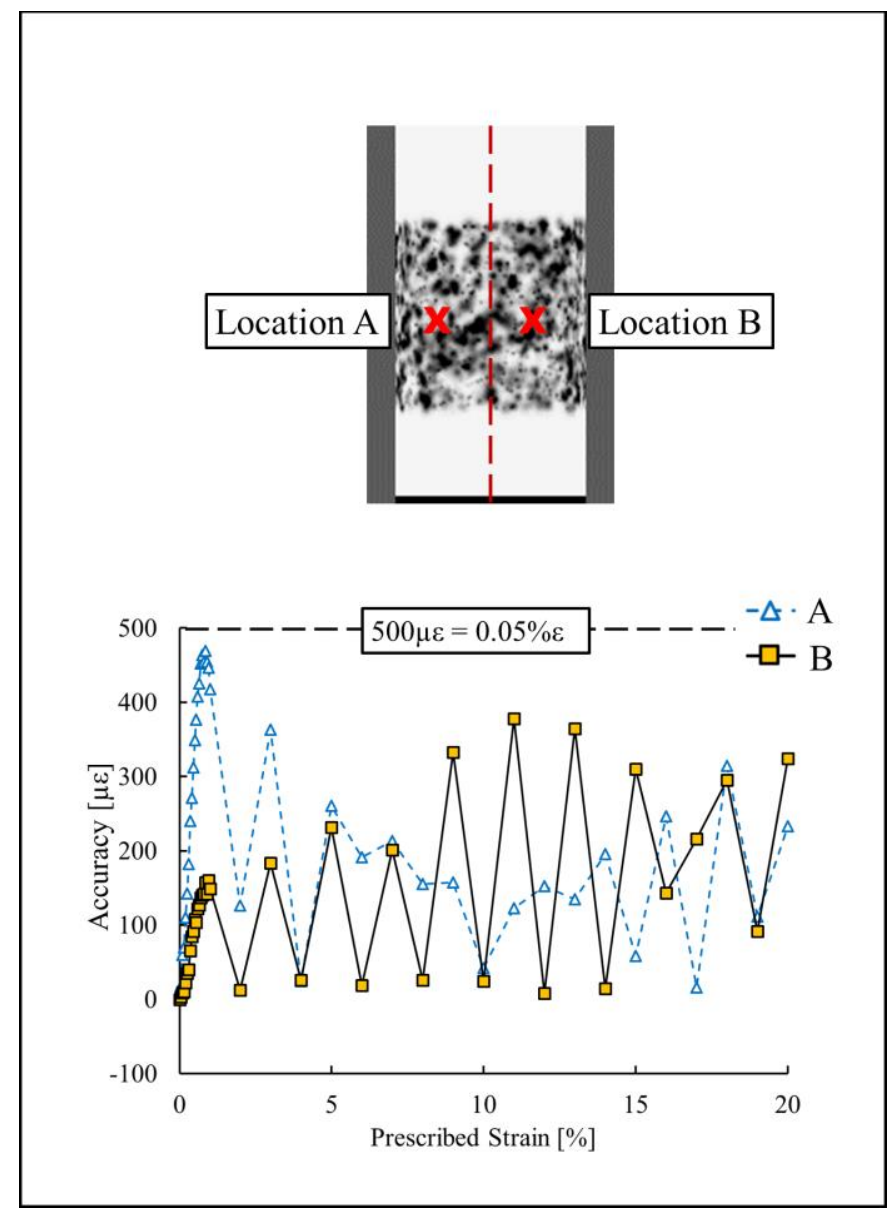

Figure 5. Effects off-axis subset on the accuracy value.

In conclusion, the 2-D DIC accurately predicts the mechanical strain of a speckle pattern at different loading paths without a significant increase in the inaccuracy along the centerline. When the subset location is off the centerline of the tube sample, maximum inaccuracy increased to $469 \mu \varepsilon(0.047 \%)$. This value still offers acceptable resolution for ductile materials.

\section{FAILURE BEHAVIOR OF SiC/SiC COMPOSITES DURING PCMI LOADING}

This section describes the mechanical response of $\mathrm{SiC} / \mathrm{SiC}$ composites during a PCMI type of loading at various pressurization rates (i.e., strain rates). The characteristics of the $\mathrm{SiC} / \mathrm{SiC}$ composite tubes were listed in the FY 2017 Oak Ridge National Laboratory Nuclear Technology Research and Development L3 report [6].

An example mechanical response of a $\mathrm{SiC} / \mathrm{SiC}$ composite tube sample during the test is shown in Figure 6. This sample was subjected to a pressurization rate of $\sim 3 \mathrm{GPa} / \mathrm{s}$, and the duration of the simulated RIA event was $52 \mathrm{~ms}$ (from loading to rupture of the specimen). Frame 1 was taken before the mechanical test and shows the four projections of the sample. Frame 2 shows the upward movement of the mechanical system due to the impact caused by the penetration of the driver tube. Frame 3 shows the moment at which the failure strains were calculated before the rupture of the $\mathrm{SiC} / \mathrm{SiC}$ composite sample. All samples tested in this study were failed in an analogous manner as shown in frame 4. The deformation was localized to the thin region of the driver tube, and except for one test, the cracks did not propagate in the axial direction. 

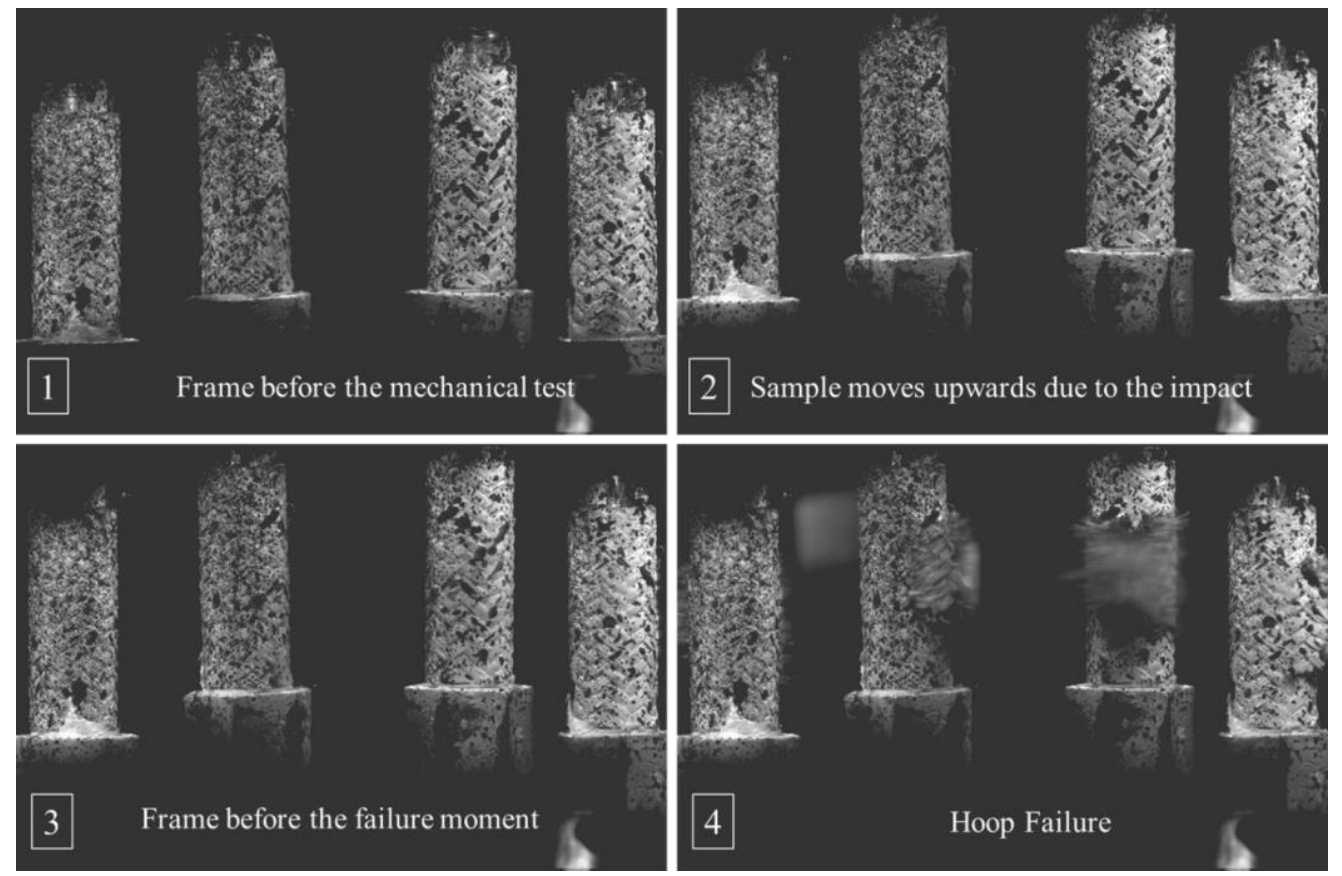

Figure 6. Projections of a $\mathrm{SiC} / \mathrm{SiC}$ composite sample that was tested at a pressurization rate of. $3 \mathrm{GPa} / \mathrm{s}$

Figure 7a shows the evolution of the internal pressure of the driver tube and the DIC-calculated mechanical strains on the sample surface, which was subjected to a pressurization rate of $3.6 \mathrm{GPa} / \mathrm{s}$. The internal pressure (black curve in Figure 7a) increases from 15.4 to $203 \mathrm{MPa}$ in $52 \mathrm{~ms}$. The sample was ruptured at about $203 \mathrm{MPa}$ of internal pressure. The diametral strain showed two distinct slopes over time. The initial slope (strain rate) was $0.6 / \mathrm{s}$ up to the strain value of $0.2 \%$, and the strain rate was increased to $5.4 / \mathrm{s}$ after the strain value of $0.2 \%$ until the sample fractured. The axial strain was constant during the test but showed small fluctuations due to possible hydraulic oil redistribution during impact.

A high-speed camera enabled observation of sample failure in situ. Figure $7 \mathrm{~b}$ shows a clear, detailed picture of the $\mathrm{SiC} / \mathrm{SiC}$ composite sample failing at a strain value of $0.87 \%$ during the moment of fracture. The sample ruptured in the hoop direction as shown by the white line on the sample surface and the cracks branched out (yellow lines) along the major fiber axis. Crack propagation was avoided because of the branching. Furthermore, minor cracking on the fibers (red line) were also identified. 

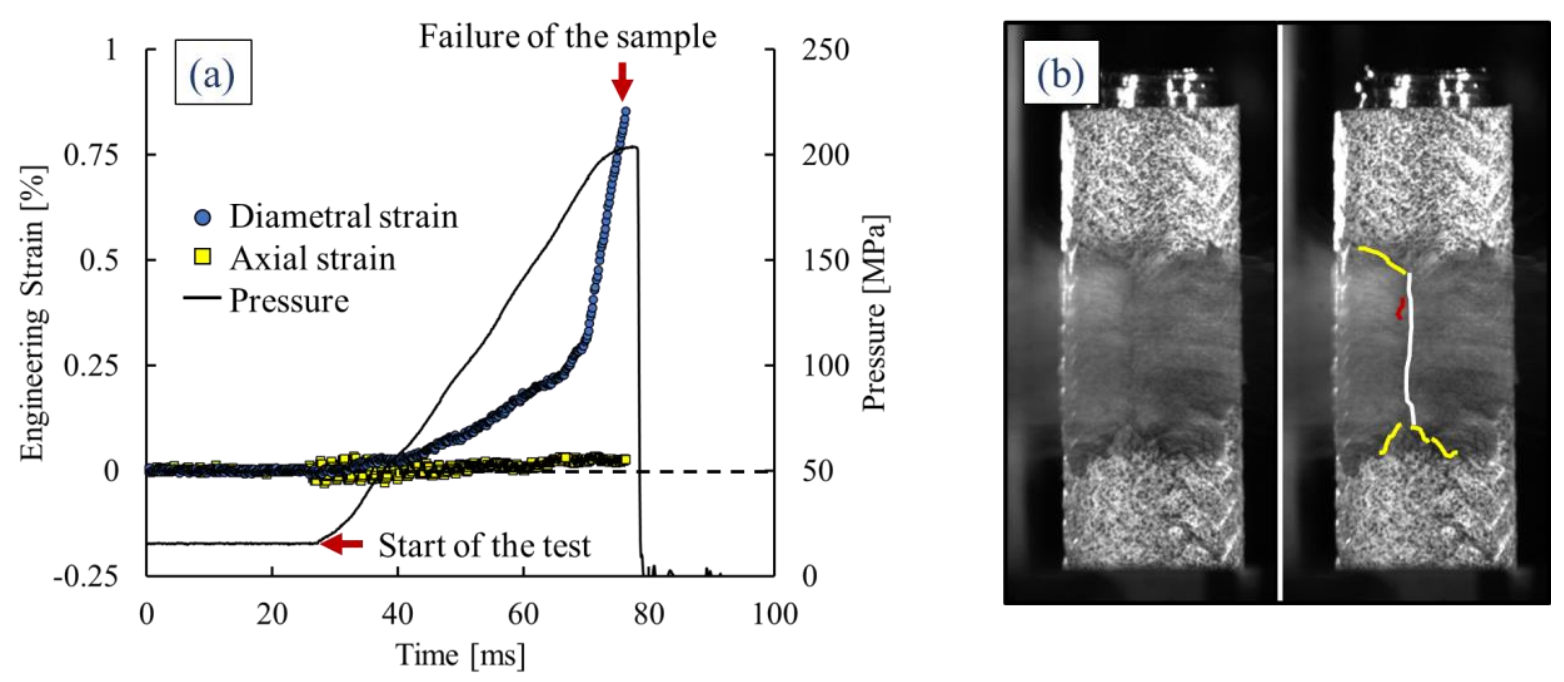

Figure 7. (a) Evolution of the engineering strain and the internal pressure of the driver tube. (b) Outer surface of the $\mathrm{SiC} / \mathrm{SiC}$ composite samples at the moment of failure. White line depicts the major hoop crack that yielded failure. Yellow lines show cracks branching out from the major hoop crack, and the red line is a surface crack on the fibers.

Table 1 summarizes the mechanical test results of $\mathrm{SiC} / \mathrm{SiC}$ composites. Because the mechanical tests aimed to simulate RIA pulse widths of the Transient Reactor Test Facility (TREAT) (from $\sim 50$ to $>100 \mathrm{~ms}$ ), CABRI ( 20 ms), and Nuclear Safety Research Reactor (NSRR) ( 10 ms) integral tests [5], each pressurization rate corresponds to a specific energy deposition rate during various RIA events. For instance, the pressurization rates of 1.75 correspond to TREAT's clipped pulse; $3.6 \mathrm{GPa} / \mathrm{s}$ was similar to TREAT's pulse with ${ }^{3} \mathrm{He}$ shutdown system and CABRI, and $18 \mathrm{GPa} / \mathrm{s}$ was similar to the Nuclear Safety Research Reactor [5]. One sample was tested at a slower pressurization rate of $1.75 \mathrm{GPa} / \mathrm{s}$, where the overall event time was $100 \mathrm{~ms}$. That sample failed at a diametral strain rate of $1.16 \%$. Other tests were performed at higher pressurization rates, and three samples were used for each pressurization rate. The samples tested at pressurization level of $3.6 \mathrm{GPa} / \mathrm{s}$ were failed at $1.08 \%$ (average of three tests). The minimum value of the fracture strain was calculated as $0.87 \%$, and the maximum value was $1.21 \%$. These calculated strain values were in agreement with the reported values for similar composites, but tested under quasi-steady-state conditions [11-13].

Table 1. Summary of the mechanical test results of $\mathrm{SiC} / \mathrm{SiC}$ composites.

\begin{tabular}{cccc}
\hline $\begin{array}{c}\text { Number of } \\
\text { samples tested }\end{array}$ & $\begin{array}{c}\text { Pressurization rate } \\
{[\mathrm{GPa} / \mathrm{s}]}\end{array}$ & $\begin{array}{c}\text { Test duration } \\
{[\mathrm{ms}]}\end{array}$ & $\begin{array}{c}\text { Failure strain } \\
{[\%]}\end{array}$ \\
& 1.75 & 100 & $\mathbf{1 . 1 6}$ \\
& & & 0.87 \\
3 & 3.6 & 52 & 1.17 \\
& & & 1.21 \\
& & & (average) $\mathbf{1 . 0 8}$ \\
3 & \multirow{2}{*}{18} & 12 & 0.48 \\
& & & 0.59 \\
& & & 0.64 \\
(average) $\mathbf{0 . 5 7}$ \\
\hline
\end{tabular}

The average failure strain was decreased to $0.57 \%$ at a pressurization rate of $18 \mathrm{GPa} / \mathrm{s}$. The maximum value was $0.64 \%$, and the minimum value was $0.47 \%$. Thus, the increase in the pressurization rate from 3.6 to 
$18 \mathrm{GPa} / \mathrm{s}$ (approximately six times larger) resulted in a decrease in the average failure strain from approximately $1.08 \%$ to $0.56 \%$.

More mechanical tests, including different types of testing, are required to confirm the strain rate effect on the failure strain. However, the fracture surfaces of the samples had similar features, such as pulled-out fibers and matrix cracks in axial and radial directions. The similarity of the fracture surfaces indicates that $\mathrm{SiC} / \mathrm{SiC}$ composite still has extended load-carrying capacity with increasing strain rates, but it fails at low failure strain. Because the extended load-carrying capacity is governed by the debonding and sliding behavior of fiber/matrix interface [14], it is possible that the decreasing failure strain is caused by the change of the friction coefficient of the matrix-fiber interface during sliding with increasing pressurization rate. However, additional experimental work is needed to test this hypothesis.

\section{FeCrAI ALLOY TUBE TESTS DURING PCMI LOADING}

Unirradiated Gen-I FeCrAl alloys were subjected to a PCMI type of loading at hot zero power-relevant temperatures $\left(250^{\circ} \mathrm{C}\right)$. The Gen-I samples had an average outer diameter of $9.48 \mathrm{~mm}$ and a wall thickness of $0.45 \mathrm{~mm}$. The Gen-I FeCrAl (Fe-11.9Cr-5.98Al-0.02Y) had large grains (80-100 $\mu \mathrm{m})$, and there was no solid solution strengthening or precipitation hardening [15].

To mimic the expected microstructural development during irradiation, two types of Gen-I FeCrAl alloys were subjected to a long-term heat treatment at $\sim 479{ }^{\circ} \mathrm{C}$ in air environment for 8 months in two steps $(6$ and 2 months) to form chromium-rich $\alpha^{\prime}$ particles. ${ }^{a}$ Both alloys went through a color change due the oxide formation, as shown in Figure 8. B136Y-2 showed a darker color, which indicates a thicker layer of oxide. This difference was likely caused by the slight differences in the chromium and aluminum concentrations of the two alloys.

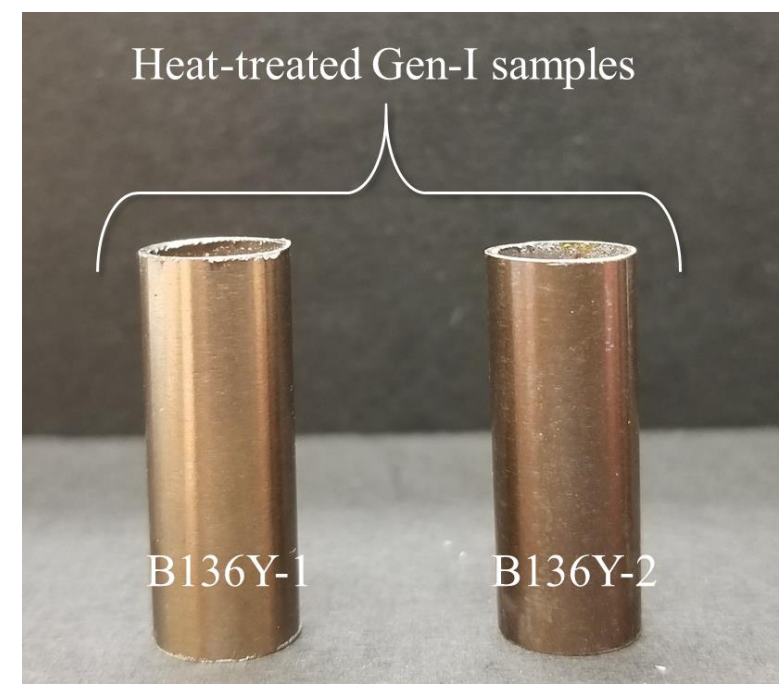

Figure 8. FeCrAl samples for MBT tests. The Gen-I alloys were subjected to a long-term heat treatment.

The mechanical tests were performed around $250{ }^{\circ} \mathrm{C}$ to simulate an RIA-relevant temperature range during the hot zero power condition of an LWR. The mechanical strain was measured with the developed DIC technique using mirrors. The high-temperature-resistant version of the first surface mirrors were used for the experiments. The sample with the driver tube, hydraulic oil, mirrors, and mirror holder attached were

\footnotetext{
${ }^{a}$ No $\alpha^{\prime}$ particles were detected after the first step. The final microstructural characterization of the heat-treated samples for $\alpha^{\prime}$ particles will be performed.
} 
heated to the specific temperature inside an insulated box (see Figures 9a and b), and soaked at hightemperature for 15-20 min. The temperature was measured using a K-type thermocouple that was attached to the samples by mechanical contact (see Figure 9c). After reaching temperature, the insulated box was removed, and test was immediately performed. Before the tests, the cooling behavior of the dummy specimen was recorded as shown in Figure 10. During the test, samples were heated to $20-25^{\circ} \mathrm{C}$ above the test temperature.
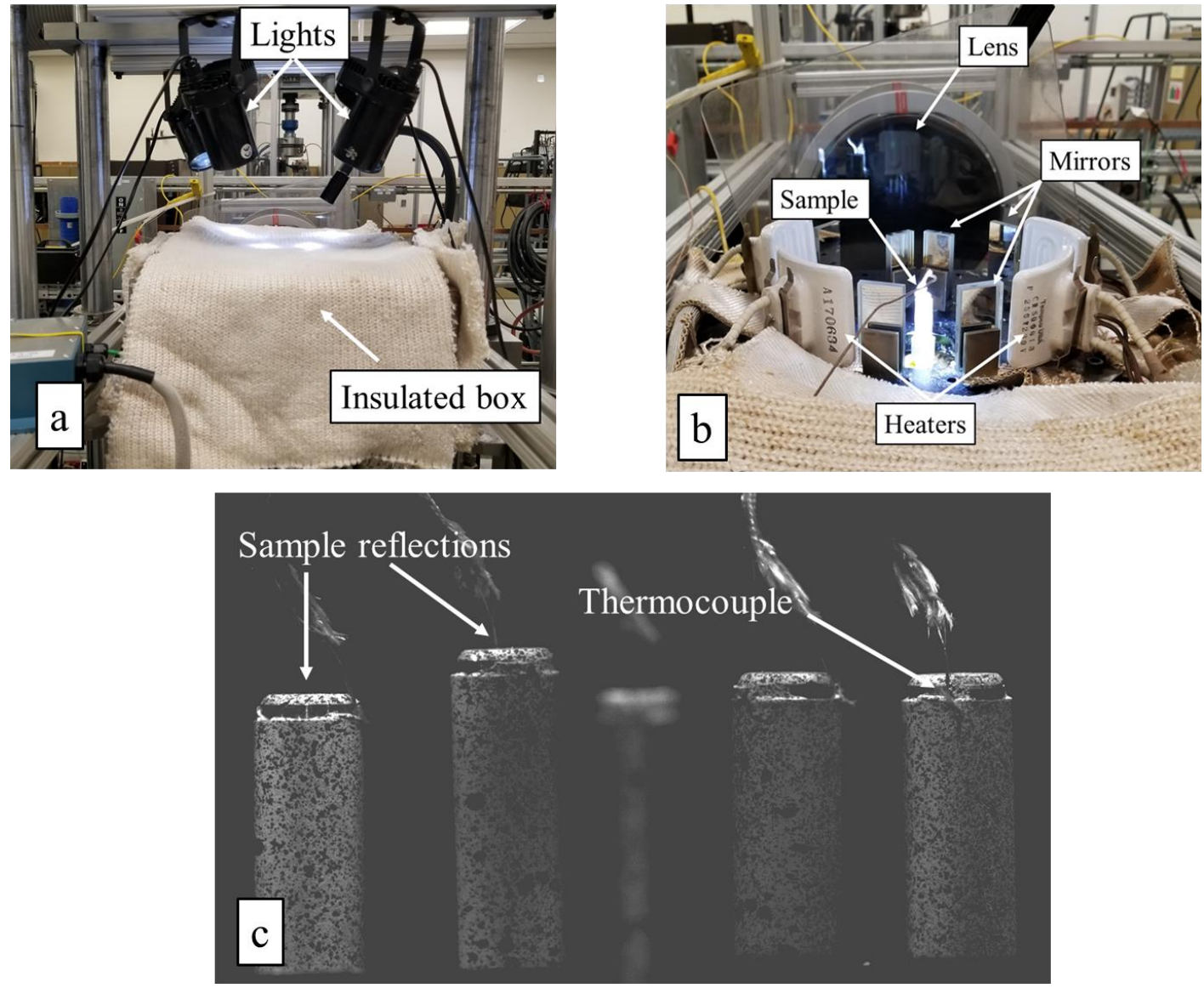

Figure 9. High-temperature setup for MBT. (a) An insulated box is placed outside the sample, heaters, and mirrors during heating. (b) The insulated box was not used during mechanical tests so that the DIC could be used. (c) Sample reflections and the location of the thermocouple. 


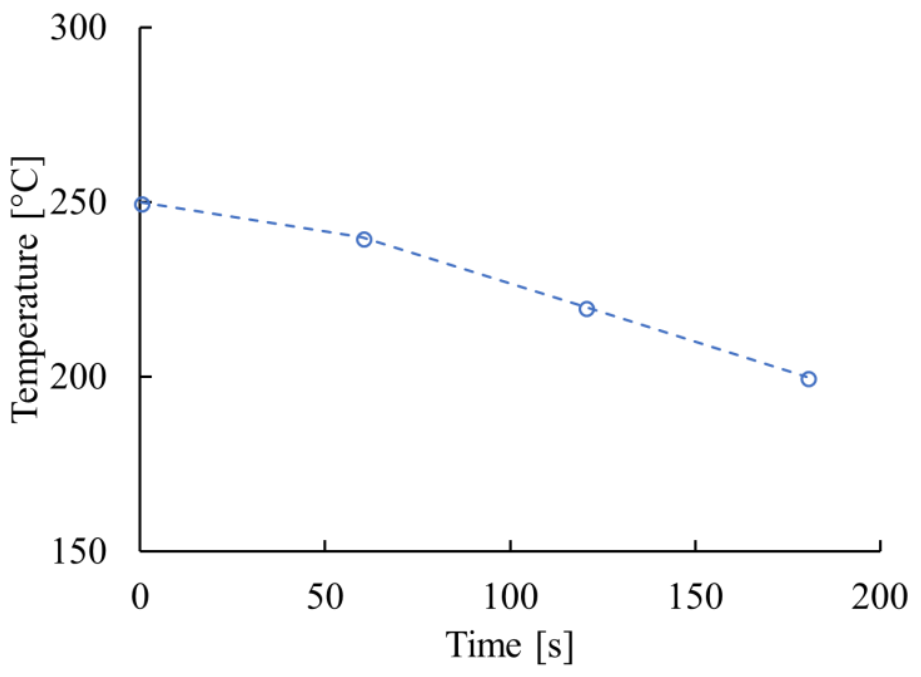

Figure 10. The cooling behavior of the dummy sample after the insulated box was removed.

Table 2 summarizes the mechanical test results of the FeCrAl alloys. Three samples were plastically deformed (bulged), and no failure occurred. The reflections of a sample during rupture is shown in Figure 11. A detailed analysis of the data informed us that the initial pressure of the driver tube in these tests was lower than that of the ruptured samples. This was likely caused by air bubble formation in the driver tube, and the measured pressure during the test represented system's pressure but not the inside of the driver tube. The strains of the bulged samples were in the range of 3.9\%-4.6\%. In general, samples which are failed during relatively slow tests showed a significant amount of ductility. B136Y-1 failed at a strain of $8.4 \%$ with the pressurization level of $2.84 \mathrm{GPa} / \mathrm{s}$, and B136Y-2 sample failed at a strain of $6.5 \%$ with the increased pressurization rate of $10.2 \mathrm{GPa} / \mathrm{s}$. 
Table 2. Results of the mechanical testing of the FeCrAl alloy.

\begin{tabular}{rcccccc}
\hline Sample & $\begin{array}{c}\text { Temperature } \\
{\left[{ }^{\circ} \mathrm{C}\right]}\end{array}$ & $\begin{array}{c}\text { Maximum } \\
\text { pressure } \\
{[\mathrm{MPa}]}\end{array}$ & $\begin{array}{c}\text { Pressurization } \\
\text { rate } \\
{[\mathrm{GPa} / \mathrm{s}]}\end{array}$ & $\begin{array}{c}\text { Test } \\
\text { duration } \\
{[\mathrm{ms}]}\end{array}$ & $\begin{array}{c}\text { Failure or } \\
\text { maximum } \\
\text { strain } \\
{[\%]}\end{array}$ & Test result \\
\hline \multirow{2}{*}{ B136Y-1 } & 255 & 175.3 & 2.84 & 61.6 & 8.40 & Failed \\
& 250 & 171.9 & 7.70 & 22.3 & 4.64 & Bulged \\
& 251 & 186.7 & 9.33 & $20.0^{\mathrm{i}}$ & 4.51 & Bulged \\
\hline B136Y-2 & 248 & 189.9 & 3.24 & 58.6 & N/A & Ruptured \\
& 250 & 181.0 & 9.0 & $20.2^{\mathrm{i}}$ & 3.92 & Bulged \\
& 251 & 209.9 & 10.2 & 20.6 & 6.52 & Ruptured \\
\hline
\end{tabular}

${ }^{\mathrm{i}}$ It is the pressure rise time for the bulged samples.

${ }^{\text {ii }}$ Camera did not trigger during this experiment. No images were collected.
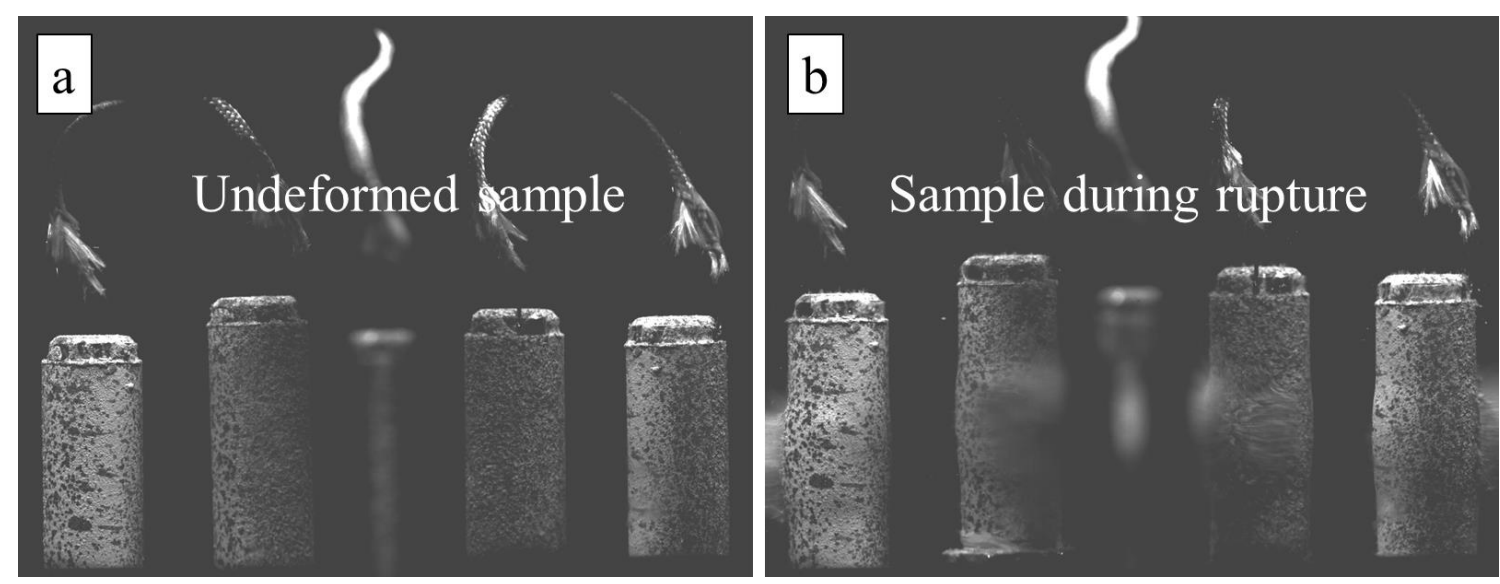

Figure 11. Four reflections of the FeCrAl sample. (a) Before test and (b) during rupture.

\section{RELEVANCE TO THE RIA SAFETY ENVELOPE}

A typical set of pulse widths for a super-prompt critical RIA is illustrated in Figure 12 as a function of inserted reactivity for three different neutron generation times. Note that each value of reactivity inserted the energy deposition, and so mechanical loading imposed on the cladding will be roughly the same even though the neutron generation time will drive shorter pulses. The imposed strain depends on reactivity, but the strain rate depends on both the reactivity and the neutron generation time. For $\mathrm{SiC} / \mathrm{SiC}$ composites, the expected failure strain $(0.57 \%-1.2 \%)$ is similar to the expected PCMI-strain induced by the unconstrained thermal expansion of uranium dioxide fuel, under the assumption of the closed fuel-cladding gap, for $\mathrm{SiC} / \mathrm{SiC}$ pressurized water reactor core designs for hot zero power RIA [17]. Thus, fuel assemblies with $\mathrm{SiC} / \mathrm{SiC}$ cladding should be designed to mitigate possible effects due to the gap closure during a postulated RIA.

The failure strain is larger for the fresh FeCrAl specimens, B136Y-2 than the SiC/SiC composites. However, the decrease in the failure strain (from $\sim 8.5 \%$ to $\sim 6.5 \%$ ) has been observed for the B136Y alloy family. This indicates further study focusing on the strain-rate effect is needed for the investigation of the 
safety limits of the $\mathrm{C}$-series $\mathrm{FeCrAl}$ alloys which are being developed for the nuclear fuel cladding applications .

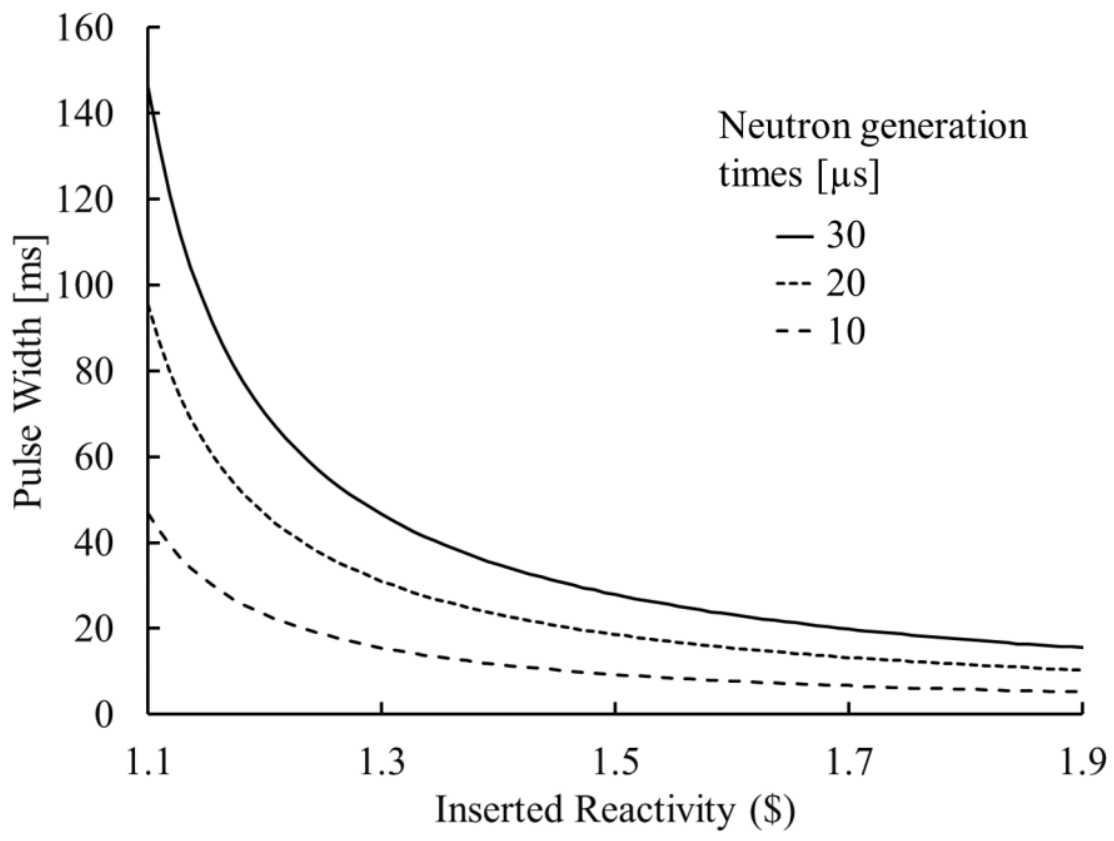

Figure 12. Example calculated pulse widths of a typical RIA in an LWR for different neutron generation times ranging from 10 to $30 \mu \mathrm{s}$ and reactivity insertions, calculated using point kinetics with onedimensional thermal feedback.

\section{SUMMARY AND FUTURE WORK}

The mechanical behavior of the ATF cladding candidates of $\mathrm{SiC} / \mathrm{SiC}$ composites and $\mathrm{FeCrAl}$ alloys during a PCMI-type of loading at RIA relevant strain rates was investigated in this work. To accomplish this, we used a pulse-controlled MBT device with $360^{\circ}$-view DIC option. Before the tests, we verified the DICcalculated strains using virtually generated speckle patterns under different strain paths. These images were generated in the $x-y$ plane and then wrapped into a cylinder. Analysis of the virtual images showed an excellent accuracy of the calculated strains for the tube's centerline locations. For the off-centerline locations, the inaccuracy increased to $0.047 \%$ (maximum).

The mechanical response of the $\mathrm{SiC} / \mathrm{SiC}$ composites was investigated at various pressurization rates that correspond to different RIA scenarios. The failure strain decreased from $1.2 \%$ to $0.57 \%$ while the duration of the PCMI loading decreased from 100 to $10 \mathrm{~ms}$. A change in the friction coefficient between the fibermatrix interface was hypothesized to explain the observed behavior.

The MBT results of FeCrAl samples that were subjected to a long-term heat treatment (B136Y alloys) retained a good amount of ductility at high pressurization rates.

The design envelope of nuclear fuel with $\mathrm{SiC} / \mathrm{SiC}$ composites is limited because of the low fracture strain of these composites. The failure strain of the fresh $\mathrm{FeCrAl}$ samples indicates that PCMI failure during RIA is unlikely for fresh FeCrAl. Further testing to understand the behavior of irradiated samples with degraded mechanical properties is recommended.

The research plan for FY 2019 will include two major activities related to the RIA testing and the transient test development of the upgoing mini-fuel project. A pulse-controlled MBT with the $360^{\circ}$-view DIC option is a unique capability; however, the mechanical testing of the irradiated specimens in hot cells using MBT requires extensive research. In our previously published paper [5], the validation tests of zirconium alloys 
indicated that the PST test produces similar failure strains and similar loading-paths relative to MBT. We will develop a PST testing capability for the irradiated samples. This activity is envisioned to eventually include machining of PST samples in a hot cell environment, testing of unirradiated samples to connect the data produced by MBT and PST, and the mechanical tests of the irradiated cladding.

The second activity will aim to develop a safety envelope for the advanced fuel forms including ATF under transient conditions. The MiniFuel irradiation capability at ORNL will provide key fundamental nuclear fuel safety data on nuclear fuel materials, including information about fission gas release, microstructure evolution, mechanical properties, and other important behaviors. Extension and adaptation of this irradiation methodology to provide data relevant to PCMI introduces new challenges, but a plan to explore the viability of such a test will be developed. 


\section{REFERENCES}

[1] N. R. Brown, M. Todosow, A. Cuadra, Screening of advanced cladding materials and $\mathrm{UN}-\mathrm{U}_{3} \mathrm{Si}_{5}$ fuel, J. Nucl. Mater. 462 (2015) 26-42. doi:10.1016/j.jnucmat.2015.03.016.

[2] J. Desquines, D. A. Koss, A. T. Motta, B. Cazalis, M. Petit, The issue of stress state during mechanical tests to assess cladding performance during a reactivity-initiated accident (RIA), $J$. Nucl. Mater. 412 (2011) 250-267. http://www.sciencedirect.com/science/article/pii/S002231151100273X.

[3] F. Nagase, T. Fuketa, Investigation of hydride rim effect on failure of Zircaloy-4 cladding with tube burst test, J. Nucl. Sci. Technol. 42 (2005) 58-65. doi:10.1080/18811248.2005.9726364.

[4] K. Yueh, J. Karlsson, J. Stjärnsäter, D. Schrire, G. Ledergerber, C. Munoz-Reja, L. Hallstadius, Fuel cladding behavior under rapid loading conditions, J. Nucl. Mater. 469 (2016) 177-186. doi:10.1016/j.jnucmat.2015.11.032.

[5] M. N. Cinbiz, N. R. Brown, K. A. Terrani, R.R. Lowden, D. Erdman, A pulse-controlled modified-burst test instrument for accident-tolerant fuel cladding, Ann. Nucl. Energy. 109 (2017) 396-404. doi:10.1016/j.anucene.2017.05.058.

[6] M. N. Cinbiz, N. R. Brown, R. R. J. Lowden, K. Linton, K. A. Terrani, RIA simulation tests using driver tube for ATF cladding, Oak Ridge, 2017.

https://info.ornl.gov/sites/publications/Files/Pub75755.pdf.

[7] P. Bing, X. Hui-min, X. Bo-qin, D. Fu-long, Performance of sub-pixel registration algorithms in digital image correlation, Meas. Sci. Technol. 17 (2006) 1615.

[8] T. Fuketa, 2.22 - Transient response of LWR fuels (RIA), in: Compr. Nucl. Mater., 2012: pp. 579-593. doi:10.1016/B978-0-08-056033-5.00044-6.

[9] S. Leclercq, G. Rousselier, G. Cailletaud, A generic method for modeling the behavior of anisotropic metallic materials: Application to recrystallized zirconium alloys, Mech. Mater. 39 (2007) 458-472. doi:10.1016/j.mechmat.2006.07.002.

[10] T. M. Link, D. A. Koss, A. T. Motta, Failure of Zircaloy cladding under transverse plane-strain deformation, Nucl. Eng. Des. 186 (1998) 379-394.

[11] E. Rohmer, E. Martin, C. Lorrette, Mechanical properties of $\mathrm{SiC} / \mathrm{SiC}$ braided tubes for fuel cladding, J. Nucl. Mater. 453 (2014) 16-21. doi:10.1016/j.jnucmat.2014.06.035.

[12] F. Bernachy-Barbe, L. Gélébart, M. Bornert, J. Crépin, C. Sauder, Anisotropic damage behavior of SiC/SiC composite tubes: Multiaxial testing and damage characterization, Compos. Part A Appl. Sci. Manuf. 76 (2015) 281-288. doi:https://doi.org/10.1016/j.compositesa.2015.04.022.

[13] K. Shapovalov, G. M. Jacobsen, L. Alva, N. Truesdale, C. P. Deck, X. Huang, Strength of SiCfSiCm composite tube under uniaxial and multiaxial loading, J. Nucl. Mater. 500 (2018) 280-294. doi:https://doi.org/10.1016/j.jnucmat.2018.01.001.

[14] R. Francis, L. Jacques, N. Roger, L. Edgar, F.M. K., B.T. M., Interfacial bond strength in $\mathrm{SiC} / \mathrm{C} / \mathrm{SiC}$ composite materials, as studied by single-fiber push-out tests, J. Am. Ceram. Soc. 81 (2005) 965-978. doi:10.1111/j.1151-2916.1998.tb02434.x.

[15] Y. Yamamoto, B. A. Pint, K. A. Terrani, K. G. Field, Y. Yang, L. L. Snead, Development and property evaluation of nuclear grade wrought FeCrAl fuel cladding for light water reactors, $J$. Nucl. Mater. 467 (2015) 703-716. doi:10.1016/j.jnucmat.2015.10.019.

[16] Y. Yamamoto, Z. Sun, B. A. Pint, K. A. Terrani, Optimized Gen-II FeCrAl cladding production in large quantity for campaign testing, Report no. ORNL/TM-2016/227. Oak Ridge National Laboratory, Oak Ridge, TN, 2016. Available: http://info.ornl.gov/sites/publications/files/Pub67815.pdf.

[17] N. R. Brown, A. J. Wysocki, K. A. Terrani, K. Xu, D. M. Wachs, The potential impact of enhanced accident tolerant cladding materials on reactivity initiated accidents in light water reactors, Ann. Nucl. Energy. (2016). doi:http://dx.doi.org/10.1016/j.anucene.2016.09.033. 